\title{
The T/ebp null mouse: thyroid-specific enhancer-binding protein is essential for the organogenesis of the thyroid, lung, ventral forebrain, and pituitary
}

\author{
Shioko Kimura, ${ }^{1,2}$ Yoshinobu Hara, ${ }^{3}$ Thierry Pineau, ${ }^{1}$ Pedro Fernandez-Salguero, ${ }^{1}$ Cecil H. Fox, ${ }^{4}$ \\ Jerrold M. Ward, ${ }^{5}$ and Frank J. Gonzalez ${ }^{1}$ \\ ${ }^{1}$ Laboratory of Molecular Carcinogenesis, National Cancer Institute; ${ }^{3}$ Laboratory of Biochemical Genetics, National Heart, \\ Lung, and Blood Institute, National Institutes of Health, Bethesda, Maryland 20892 USA; ${ }^{4}$ Molecular Histology Laboratory, \\ Gaithersburg, Maryland 20897 USA; and ${ }^{5}$ Veterinary and Tumor Pathology Section, Office of Laboratory Animal Science, \\ National Cancer Institute, Frederick, Maryland 21702-1201 USA
}

The thyroid-specific enhancer-binding protein (T/ebp) gene was disrupted by homologous recombination in embryonic stem cells to generate mice lacking T/EBP expression. Heterozygous animals developed normally, whereas mice homozygous for the disrupted gene were born dead and lacked the lung parenchyma. Instead, they had a rudimentary bronchial tree associated with an abnormal epithelium in their pleural cavities. Furthermore, the homozygous mice had no thyroid gland but had a normal parathyroid. In addition, extensive defects were found in the brain of the homozygous mice, especially in the ventral region of the forebrain. The entire pituitary, including the anterior, intermediate, and posterior pituitary, was also missing. In situ hybridization showed that the T/ebp gene is expressed in the normal thyroid, lung bronchial epithelium, and specific areas of the forebrain during early embryogenesis. These results establish that the expression of T/EBP, a transcription factor known to control thyroid-specific gene transcription, is also essential for organogenesis of the thyroid, lung, ventral forebrain, and pituitary.

[Key Words: T/EBP; gene targeting; thyroid; lung; ventral forebrain; pituitary]

Received August 22, 1995; revised version accepted November 10, 1995.

Thyroid-specific enhancer-binding protein $(\mathrm{T} / \mathrm{EBP})$ binds to an enhancer element located $\sim 5.5 \mathrm{~kb}$ upstream of the human thyroid peroxidase gene transcription start site and regulates thyroid-specific gene expression (Kikkawa et al. 1990; Mizuno et al. 1991). T/EBP, also named thyroid-specific transcription factor 1 (TTF-1) or $\mathrm{Nkx}-2.1$, was originally described to govern thyroid-specific expression of the rat thyroglobulin gene /Civitareale et al. 1989|. Several studies have established the role of T/EBP in expression of genes encoding thyroid peroxidase /Kikkawa et al. 1990; Mizuno et al. 1991; Abramowicz et al. 1992; Francis-Lang et al. 1992), thyroglobulin (Civitareale et al. 1989), and the thyrotropin (TSH) receptor (Civitareale et al. 1993; Shimura et al. 1994). All three proteins are essential for thyroid hormone biosynthesis (DeGroot and Niepomniszcze 1977). T/EBP is also expressed in the lung (Guazzi et al. 1990; Mizuno et al. 1991), and it has been recently demonstrated that the expression of genes encoding the lung surfactant proteins $A$ and $B$ is regulated by this DNA-binding protein (Bohinski et al. 1994; Bruno et al. 1995).

${ }^{2}$ Corresponding author.
$T / e b p(N k x-2.1)$ is the first member of the mouse $N k x-2$ gene family that is closely related to Drosophila $N K-2$ in their homeo domain sequences $168 \%-95 \%$ similarity) (Kim and Nirenberg 1989; Guazzi et al. 1990; Price et al. 1992; Lints et al. 1993). Members of the $N k x-2$ family also share a highly conserved 17-aminoacid motif that is located on the carboxyl-terminal side of the homeo domain. From the six members of this family characterized to date, the expression patterns of three genes, $T / e b p(N k x-2.1), N k x-2.2$, and $N k x-2.5$, have been studied. Lazzaro et al. (1991) have established T/eb$p(N k x-2.1)$ gene expression at $\sim 10.5$ days postcoitum (E10.5) in the thyroid anlage, fetal bronchial epithelium, and the restricted area of the forebrain during rat organogenesis. Expression of the T/ebp $(N k x-2.1)$ and $N k x$ 2.2 genes was also studied in the developing rat forebrain together with the $D l x-1$ gene, a member of a mouse gene family related to the Drosophila Distal-less (DII) gene (Price et al. 1992). The three genes are expressed in adjacent regions of the forebrain with overlapping boundaries. The $N k x-2.5$ gene is expressed at E8.5-9.5 in mouse in the pharyngal floor, a portion of which evaginates and becomes the thyroid diverticulum (Lints et al. 
1993). In contrast, the expression of the T/ebp(Nkx-2.1) gene is seen at a slightly later stage only in the thyroid diverticulum. This suggests that $N k x-2.1$ and $N k x-2.5$ may have potentially separate developmental roles. The $N k x-2.5$ gene is also expressed in early heart progenitor cells and may play a role in commitment to the myocardial lineage (Lints et al. 1993). This gene is further expressed in tongue, stomach, and spleen throughout development.

The sites and timing of T/EBP expression strongly suggest that it is required not only for regulating gene expression in the thyroid and lung but that it may also be involved in the organogenesis of the thyroid, lung, and restricted areas of the forebrain (Lazzaro et al. 1991). To assess potential roles of T/EBP in the differentiation and development of these organs, we generated a T/EBP-deficient mouse line by means of gene targeting in murine embryonic stem (ES) cells. Our results established that T/EBP is absolutely essential for the embryonic differentiation of the thyroid, the lung, and the ventral areas of the forebrain, and the pituitary.

\section{Results}

Targeted disruption of the T/ebp gene

A genomic DNA clone containing the T/ebp gene and its flanking sequences was isolated by screening a $129 / \mathrm{Sv}$ mouse genomic library (Stratagene Cloning Systems) using the rat T/ebp cDNA coding sequence as a probe (Mizuno et al. 1991; Oguchi et al. 1995). A 5.9-kb EcoRI fragment containing the entire coding and a portion of the 3 ' noncoding sequences of the T/ebp gene was used to construct a targeting vector that carries the bacterial phosphoribosyltransferase II (neo) gene as a positive selection marker and a herpes simplex virus-thymidine kinase ( $t k)$ expression cassette for negative selection of nonhomologous recombinant clones (Fig. 1A). The neo gene, which confers resistance to neomycin (G418), was inserted into an XhoI site in the middle of the second exon of the $T / e b p$ gene, resulting in the disruption of the first helix of the homeo domain sequence.

J1 ES cells (Li et al. 1992) were transfected with the linearized targeting vector by electroporation, and G418resistant colonies were selected and screened for disruption of the T/ebp gene by Southern blotting using as a probe a sequence external to the genomic fragment for homologous recombination (Fig. 1A). Of $\sim 1600$ G418resistant clones screened, only one was a homologous recombinant. This clone, which exhibits the expected pattern for the disruption of exon two, was injected into C57BL/6N (B6) mouse blastocysts to produce chimeric animals. Five of nine chimeric males transmitted the ES cell genome to their progeny. Stul digestion of mouse tail genomic DNA generated a fragment of $7.5 \mathrm{~kb}$ for the targeted allele that is smaller than the wild-type fragment $(14 \mathrm{~kb})$ because of the presence of this restriction site within the neo gene (Fig. 1B).

\section{T/ebp null animals were stillborn and normal lung and thyroid were missing}

Matings between heterozygotes $(+/-)$ for the targeted allele resulted in $\sim 25 \%$ lethality, which agreed with the

\section{A}
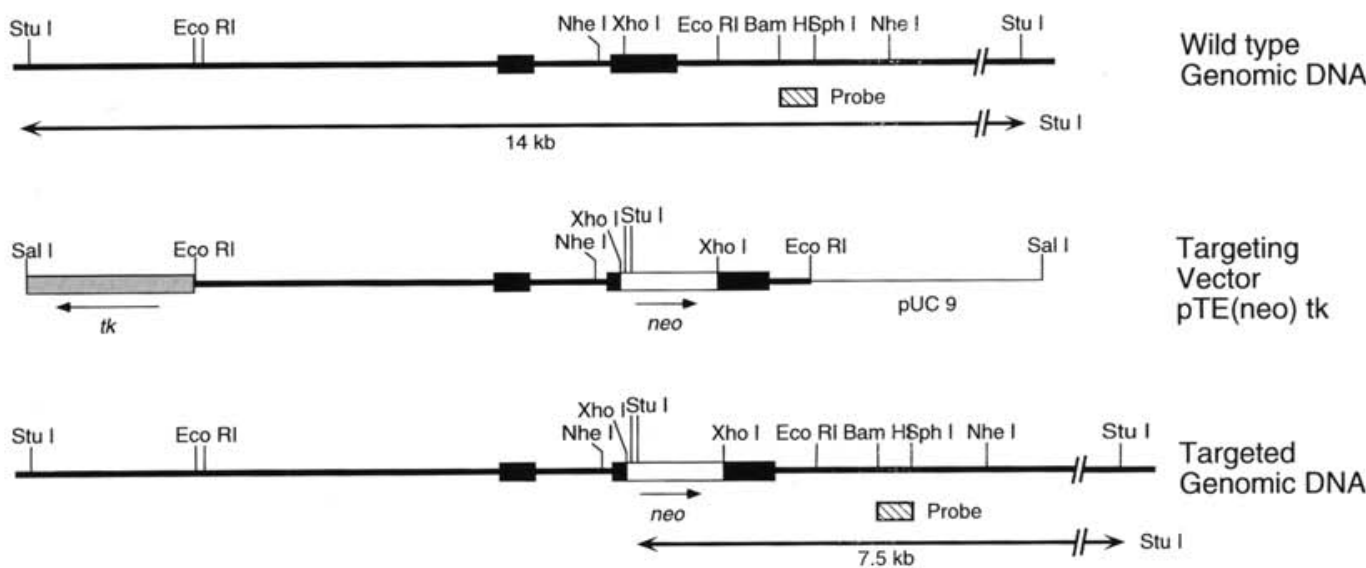

\section{B}

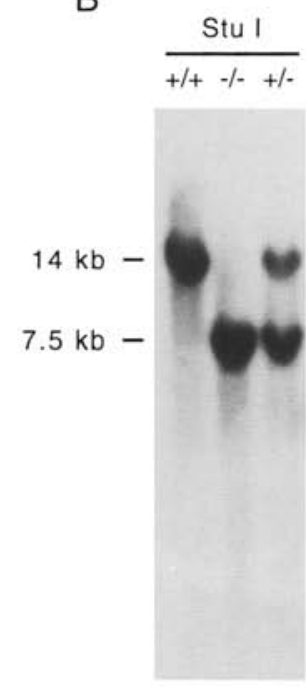

Figure 1. Production of T/EBP-deficient mice by homologous recombination in ES cells. $(A)$ Schematic representation of the mouse $T / e b p$ gene, the targeting vector, and the targeted allele. The coding region of the T/ebp gene is shown by solid boxes; the thin line outlines pUC9 vector sequence. The pMCl-neo cassette (neo) and the herpes simplex virus thymidine kinase gene $(t k)$ are indicated by an open and a shaded box, respectively. Arrows below the boxes indicate the direction of transcription. Restriction enzyme cleavage sites, the location of a genomic probe (hatched box) used to confirm homologous recombination, and the expected fragment sizes are indicated. (B) Typical genomic Southern blot analyses on wild-type $(+1+1$, heterozygous $1+1-1$, and homozygous $|-|-\mid$ mutant mice. Genomic DNAs were isolated from tails of mice and digested with StuI. 
expected Mendelian distribution for a recessive lethal trait. Homozygous mice apparently died at birth without any sign of activity. However, they were alive when sacrified just before birth at E19.5. Their weight represented $\sim 85 \%$ of that from healthy littermates. Mice heterozygous for the disrupted T/ebp allele were born and developed normally. Necropsy of the homozygous mutant mice revealed that the lungs were absent (Fig. 2). They displayed instead dilated sac-like structures in their pleural cavities. Although in most of the cases examined, this sac-like structure appeared to be present in only the right pleural cavity (data not shown), it was also observed occasionally in only the left cavity. In one mouse, both pleural cavities contained the sac-like structures (Fig. 2B), indicating that these structures could be either singular or multicystic.

Histological analyses were performed to study the morphology of the sac-like structures (Fig. 3). The heart, thymus, and parietal pleura were found to be histologically normal (Fig. 3C). Because a detailed analysis of the pulmonary vessels has not been conducted, however, the possibility remains that the pulmonary artery is not normal, as it now supplies a greatly reduced organ. Occasionally, a grossly abnormal anatomy of the thoracic vessels was seen. The sac-like structure was apparently a rudimentary bronchial tree. The appearance of this rudimentary bronchial tree varied from mouse to mouse; some had many cystic bronchial branches (Figs. 2D and 3B), whereas others had only a few (Fig. 2C). The rudimentary bronchial tree sometimes consisted of a large central cavity, a narrow outer rim of the epithelium, and a supporting stroma (Fig. 3C). The epithelium also exhibited variations from normal appearance with simple cuboidal or columnar cells to more abnormal bronchial epithelium, including multiple layers of cells, apparent syncytial cells, and hyperchromatic cells (Fig. 3D,E). In some mice, the lumina of the rudimentary bronchial trees contained abundant keratin-like debris. However, in all of the homozygous mice analyzed no normal pul- monary parenchyma with bronchioli or alveoli were present (Fig. 3B). Thus, it appears that the progressive development of the lower bronchial tree, which should be clearly seen by E12.5-13 (Kaufman 1992) did not take place and that the development of normal lung was arrested at some time around this stage.

Homozygous mice were also histologically examined for the thyroid. They had normal parathyroids, but no thyroid gland epithelium was seen at any location along the head and neck (Fig. 3F,G) despite extensive serial sectioning to attempt to locate the thyroid.

\section{Expression of the T/ebp gene during development} of the lung, thyroid, ventral forebrain, and pituitary

In situ hybridization was performed by using E11-13 B6 mouse embryos to study the pattern and time of onset of $T / e b p$ gene expression (Fig. 4). The T/ebp gene expression was clearly seen in the thyroid, lung bronchial epithelium, and the restricted areas of the forebrain. These results are similar to those obtained with rat embryos (Lazzaro et al. 1991). In the brain, T/ebp transcripts were detected most prominently in the ventral neuroepithelium and the ganglionic eminence of the forebrain (Fig. $4 \mathrm{E}, \mathrm{F})$. The expression in the ventral forebrain was seen from the septal neuroepithelium anteriorly to the mammillary neuroepithelium posteriorly. The expression, however, was not found in the ventral region of the midbrain. In most of the preoptic and hypothalamic areas $T / e b p$ transcripts were seen in the ventral region of the third ventricular neuroepithelium, in a ventrodorsal gradient with the higher expression levels in the ventral region. However, a discontinuity in T/ebp gene expression was found in the posterior wall of the preoptic recess. In this area a strikingly low level of expression was observed in parasagittal sections and, to a lesser extent, in midsagittal sections. More posteriorly, expression was continuously seen from the anterior wall of the infundibular recess to the posterior wall of the mammillary
Figure 2. Absence of the lung in T/ebp null homozygous mice. Homozygous mice, born dead, and healthy littermates, killed by carbon monoxide asphyxiation at birth, were examined. Tails were used for genotyping by Southern blot analysis. (A) Photograph of the chest region of wildtype mice. Air-inflated normal lungs are present in both pleural cavities. $(B)$ Same as $A$, but from homozygous mice with a sac-like structure (shown by an arrow) in both cavities. (C) Photograph of the heart and lung region of a wild-type (right) and a homozygous mouse (left) after removal from the chest. Sacs are shown by an arrowhead. (D) Same as $C$, but a homozygous mouse having bronchial cysts (indicated by an arrowhead). (H) Heart; (L) lung; (T) tongue; (Th) thymus.

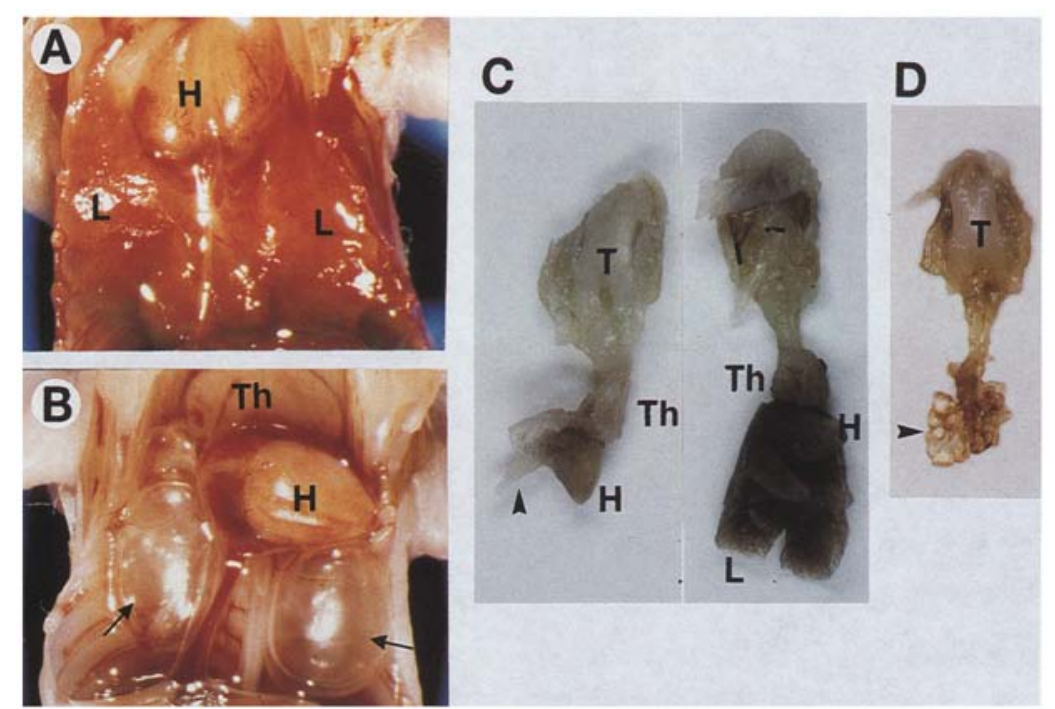




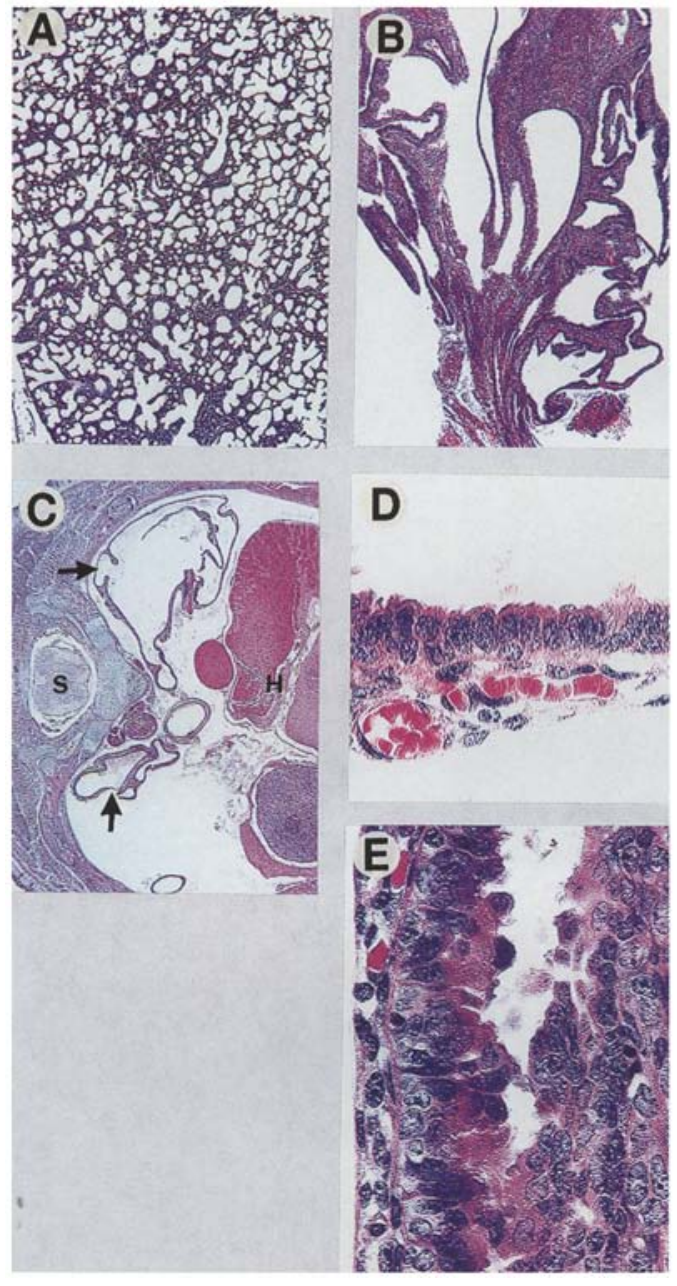

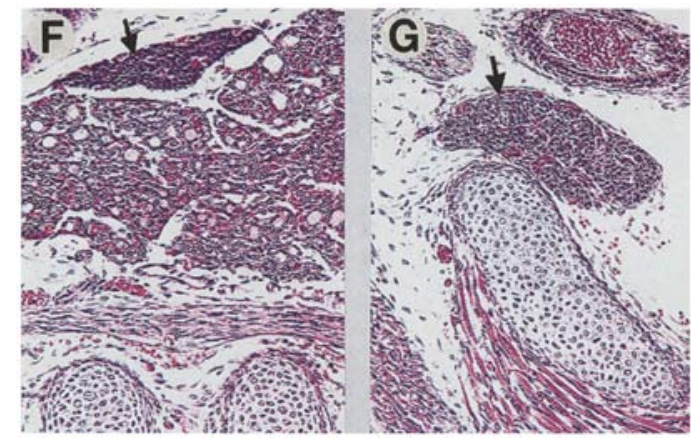

Figure 3. Histological analyses of the lung rudimentary bronchial tree and the larynx area. Newborn T/ebp null homozygous mice and sacrificed healthy littermates were fixed in $10 \%$ neutral buffered formalin, embedded in paraffin, and sagittal and transverse serial sections were stained with hematoxylin and eosin (H\&E) or periodic acid-Schiff (PAS) $(E$ only). (A) Normal lung of healthy neonate. Prominent alveoli are seen. $(B)$ Rudimentary bronchial tree showing many cystic branches of bronchus. The same magnification was used as $A$. (C) Bronchial cyst (arrow) in pleural cavity. (H) Heart; (S) spinal cord. (D) Epithelium of cystic rudimentary bronchus showing single layer of hyperchromatic cells. $(E)$ Epithelium of multicystic rudimentary bronchus showing hyperchromatic cells in multiple layers. The pleural mesothelium is seen at left; PAS. $(F)$ Parathyroid (arrow) adjacent to thyroid of normal mouse. (G) Parathyroid (arrow) with adjacent thyroid absent in homozygous mouse. recess. In the developing pituitary, T/ebp gene expression was restricted to the posterior pituitary (neurohypophysis) derived from the infundibulum of the hypothalamus. In contrast, Rathke's pouch, the primordium of the anterior, and the intermediate pituitary that derived from the oral epithelium did not express the T/ebp gene (Fig. 4G).

\section{Role of T/ebp during development of the lung} and thyroid

To identify the developmental stage at which lung and thyroid organogenesis was arrested, E12-13 and E14-15 T/ebp null homozygous and wild-type embryos were compared. Lung lobar bronchi formed by E11.5-12 start branching to form segmental bronchi by E12.5-13 (Kaufman 1992) (Fig. 5A). However, in T/ebp null homozygous mice, it appears that branching of lobar bronchi did not take place (Fig. 5B). Failure of the branching was still evident in E14-15 homozygous mice (data not shown). The E14-15 heterozygous mice exhibited the same branching morphology in their lungs as in the wildtype lung (data not shown).

Histology of thyroid development was examined using E12-13 T/ebp null homozygous and wild-type mice (Fig. $5 \mathrm{C}, \mathrm{D})$. The bilobular thyroid was apparent along the trachea in the wild type embryo. In contrast, no trace of the thyroid rudiment was found in the homozygous mouse.

\section{T/ebp null mice are missing the ventral forebrain and pituitary}

Serial sections of the brain at E18.5 were examined to identify any potential differences in the T/ebp null homozygous mouse as compared to wild-type (Figs. 6 and 7). In the $T / e b p$ null homozygous mice, extensive abnormalities were present in the ventral region of the forebrain from the septal area anteriorly to the mammillary body of the hypothalamus posteriorly. In contrast, very limited abnormalities were found in the dorsal region of the forebrain. In the septal area, the ventral region was not well separated and appeared to be fused in the mid- 
Figure 4. T/ebp expression in early embryos. In situ hybridization was carried out and the results of sagittal sections of E12-13 B6 mouse embryos are presented. Both bright-field (left) and dark-field (right) photographs are shown in $A, B, E$, and $F .(A)$ Whole embryo showing T/ebp expression in the restricted area of the brain, thyroid, and lung bronchial epithelium. (B) Enlargement of the lung in $A$ showing $T / e b p$ expression in the epithelium of the lobar and early segmental bronchi. $(C)$ Enlargement of the thyroid in $A$ showing T/ebp expression (shown by green dots). (D) Lung bronchial epithelium showing T/ebp expression (shown by green dots). (E) Parasagittal embryo brain. $|F|$ Midsagittal embryo brain. In both $E$ and $F$, the $T / e b p$ expression is present in the ventral neuroepithelium and the ganglionic eminence of the forebrain. $(G)$ Enlargement of Rathke's pouch and the infundibulum in $F$. T/ebp expression is present only in the infundibulum (shown by green dots). (Ge) Ganglionic eminence; (Hy) hypothalamus; (L) lung; (Po) preoptic area; (R) Rathke's pouch; (Thr) thyroid.
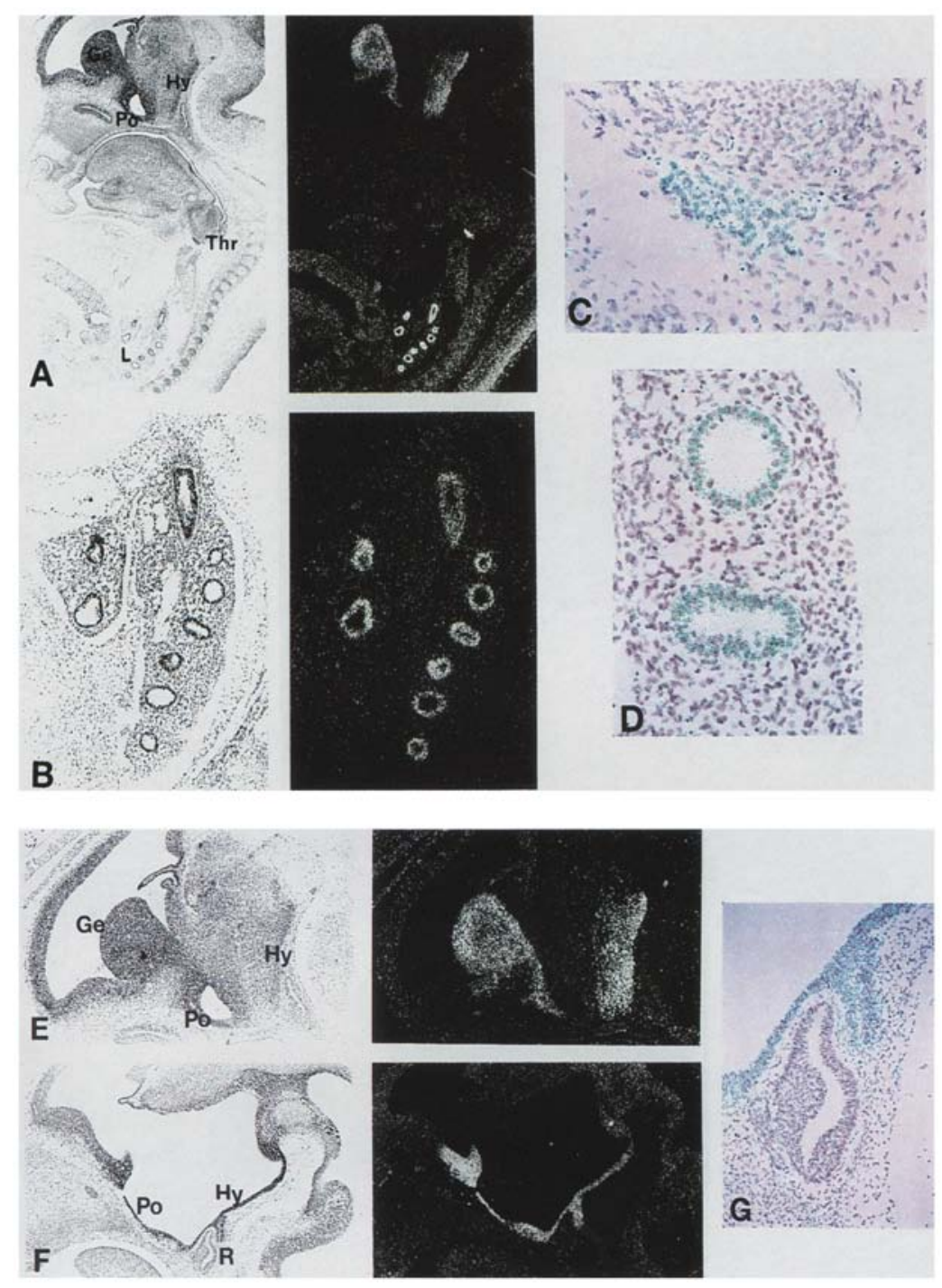

line (Fig. 6B). The typical structure of the nucleus of the diagonal band was also not observed (Fig. 6D). In the basal ganglia, abnormalities were again restricted to the ventral region and no obvious deformity was seen in the dorsal region of the striatum (Fig. 6D,F,H). In most of the preoptic and hypothalamic areas, the abnormalities were extensively observed in the ventral and medial regions and, to a lesser extent, in the dorsal and lateral regions. However, a limited degree of deformity was seen in the structure that originates from the posterior wall of the preoptic recess. The preoptic recess of the third ventricle was well developed and reached to the optic chiasma, and the suprachiasmatic nucleus was clearly identified (Fig. 6E,F). Further posteriorly, the paraventricular and supraoptic nuclei, which developed from the same origin of the dorsal hypothalamic neuroepithelium, were clearly identified (Fig. 6G,H). The anterior hypothalamic nucleus was present in a slightly reduced size, and the anterobasal nucleus was found on the floor of the diencephalon (Fig. 6G,H). From the area posterior to this level through the junction of the diencephalon and mesencephalon, extensive deformity was observed continuously. The third ventricle no longer reached to the floor of the diencephalon, and the infundibular recess and the mammillary recess were not developed in the T/ebp null homozygous mice (Figs. $6 \mathrm{H}, J, \mathrm{~L}, \mathrm{~N}$ and $7 \mathrm{~B}, \mathrm{D}, \mathrm{F})$. At the level of the tuberal hypothalamus, the ventromedial and dorsomedial nuclei were reduced in a size and appeared to be fused in the midline (Figs. 6J and 7B). The premammillary nucleus and the arcuate nucleus were not developed (Figs. 6L and 7D). Unidentified thick crossing fibers, distinct from the optic tract, were observed on the floor of the diencephalon (Figs. 6L and 7D). Completely missing were the anterior and the intermediate pituitary that originated from the oral epithelium and the posterior pituitary that was derived from the infundibulum of the diencephalon (Figs. 6L and 7D). In the posterior hypothalamus, the mammillary body and the supramammillary nucleus were not found (Figs. 6N and 7F). Further posteriorly, no obvious deformity was seen in the ventral region of the midbrain (Fig. 6P). 


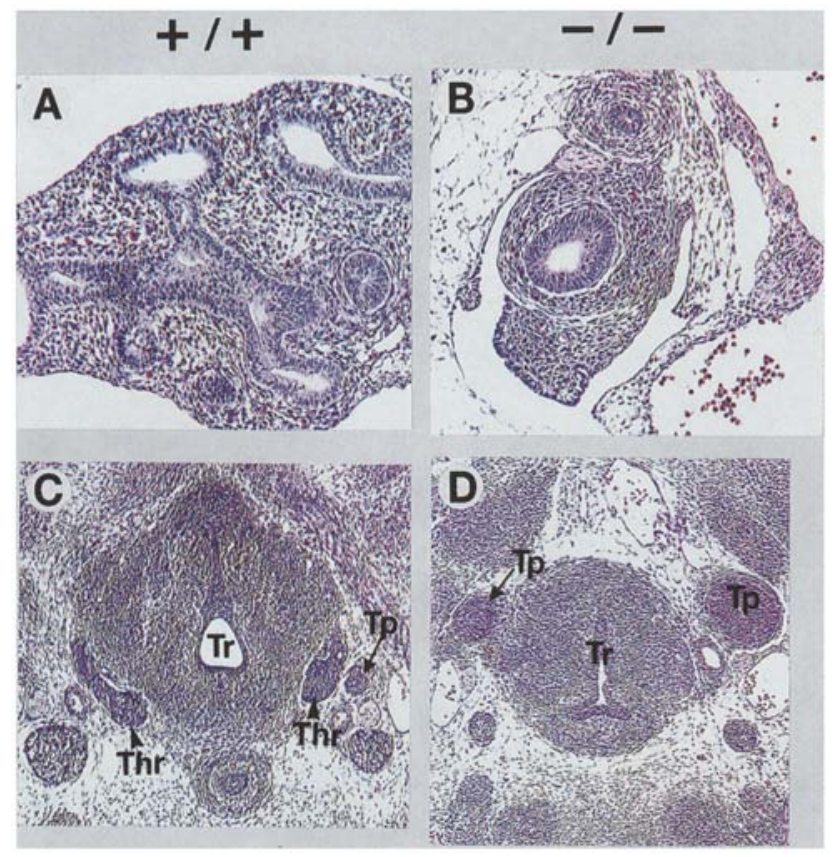

Figure 5. Development of lung and thyroid in early embryos. E12-13 wild-type $(A, C)$ and homozygous $(B, D)$ mice were fixed in $4 \%$ paraformaldehyde, and lung $(A, B)$ and thyroid $(C, D)$ were subjected to $H \& E$ staining. No branching of lobar bronchi into segmental bronchi $(B)$ and lack of thyroid $(D)$ are noted in the homozygous mouse. (Thr) Thyroid; (Tp) thymic primordium; $(\operatorname{Tr})$ trachea.

\section{Underdevelopment of the adrenal cortex in the T/ebp null mouse}

To see whether the absence of the pituitary affected the development of the adrenal cortex in homozygous mice (Capen et al. 1991), we performed histological analysis on the adrenal cortex (Fig. 8). The cells in the zona fasciculata of the adrenal cortex in homozygous mice showed an underdeveloped appearance with very little cytoplasm, whereas wild-type mice showed typical well developed cells with abundant eosinophilic granular cytoplasm. It is possible that lack of adrenocorticotropin hormone (ACTH) secretion due to the absence of the pituitary affected the development of the adrenal cortex in the homozygous mice.

\section{Discussion}

Through production and characterization of a mouse lacking T/EBP expression, we demonstrated an essential role of the mouse $T / e b p$ gene in development of the thyroid, lung, ventral forebrain, and pituitary. Our in situ hybridization results demonstrated that the $T / e b p$ gene is clearly expressed in the E11-13 mouse embryo in the thyroid, the lung epithelium, and the ventral neuroepithelium and ganglionic eminence of the forebrain. In the lung, branching of the lobar bronchi is seen at E12.5-13 in wild-type embryos (Kaufman 1992) (Fig. 5A), at which stage $T / e b p$ gene expression is clearly observed in the epithelium (Fig. 4). In contrast, at E12-13 and E14-15, T/ebp null homozygous embryos had only the lobar bronchi in their hypoplastic lungs and no further branching was found. These results clearly indicate that branching of the lower lung bronchial tree did not take place without T/EBP expression. Thus, lung development in $T / e b p$ null homozygous mice appeared to be inhibited at this stage. The abnormal epithelium and the cystic dilation found in the rudimentary bronchial tree in homozygous neonates may be the result of fruitless attempts of the epithelium to grow and branch.

The first indication of the thyroid rudiment is seen at E8.5 in the form of a thickened region of cells on the floor of the future pharynx, which then starts migrating caudally (Kaufman 1992; Rugh 1968). At E11, most of the thyroid primordium is still connected to the floor of the pharynx by the thyroglossal duct. By E13.5, the thyroglossal duct has finished bifurcating to give rise to the two lobes of the thyroid gland (Kaufman 1992; Rugh 1968). We found that the thyroid from wild-type mice clearly had two lobes around the trachea at E12-13. In the homozygous mice, however, no thyroid was found at E12-13, indicating that thyroid organogenesis was arrested before E12. Lazzaro et al. (1991) observed the expression of the $T / e b p$ gene in the thyroid rudiment at E10.5 in rats, equivalent to the stage of E9-9.5 in mouse. Whether the floor of the pharynx was evaginated in the homozygous mice still remains to be determined.

In situ hybridization results showed that the $T / e b p$ gene is expressed in the ventral neuroepithelium and the ganglionic eminence of the forebrain in E11-13 mouse. Consistent with the pattern of expression, extensive abnormalities were found in the $T / e b p$ null homozygous mice in the structure that originated from the neuroepithelium, an area in which the $T / e b p$ gene was expressed in the normal mouse. Throughout the preoptic and hypothalamic areas, the deformity was observed to be more severe in the ventral and medial areas as compared to the dorsal and lateral areas where the $T / e b p$ gene expression was found at a much lesser extent. The medial zone was reduced in size and appeared to be fused in the midline. In contrast, the deformity was limited in the lateral zone of the hypothalamus in which most of the nuclei originate from the dorsal hypothalamic neuroepithelium (Altman and Bayer 1995; Bayer and Altman 1995a,b). These include the paraventricular and supraoptic nuclei. The normal appearance of the brain was obtained at the level of the optic chiasma in E18.5 homozygous mice, which correlates very well with the presence of little T/ebp transcripts at the posterior wall of the preoptic recess at E11-13. The nuclei that develop from the neuroepithelium at the level of the preoptic recess, such as the suprachiasmatic and anterobasal nuclei (Altman and Bayer 1995; Bayer and Altman 1995a,b), also did not seem to be affected extensively. Furthermore, no $T / e b p$ gene expression was found in the ventral midbrain, which apparently looked normal.

The pituitary gland is formed by two separate developmental processes that culminate in the formation of the adenohypophysis and the neurohypophysis. The ad- 


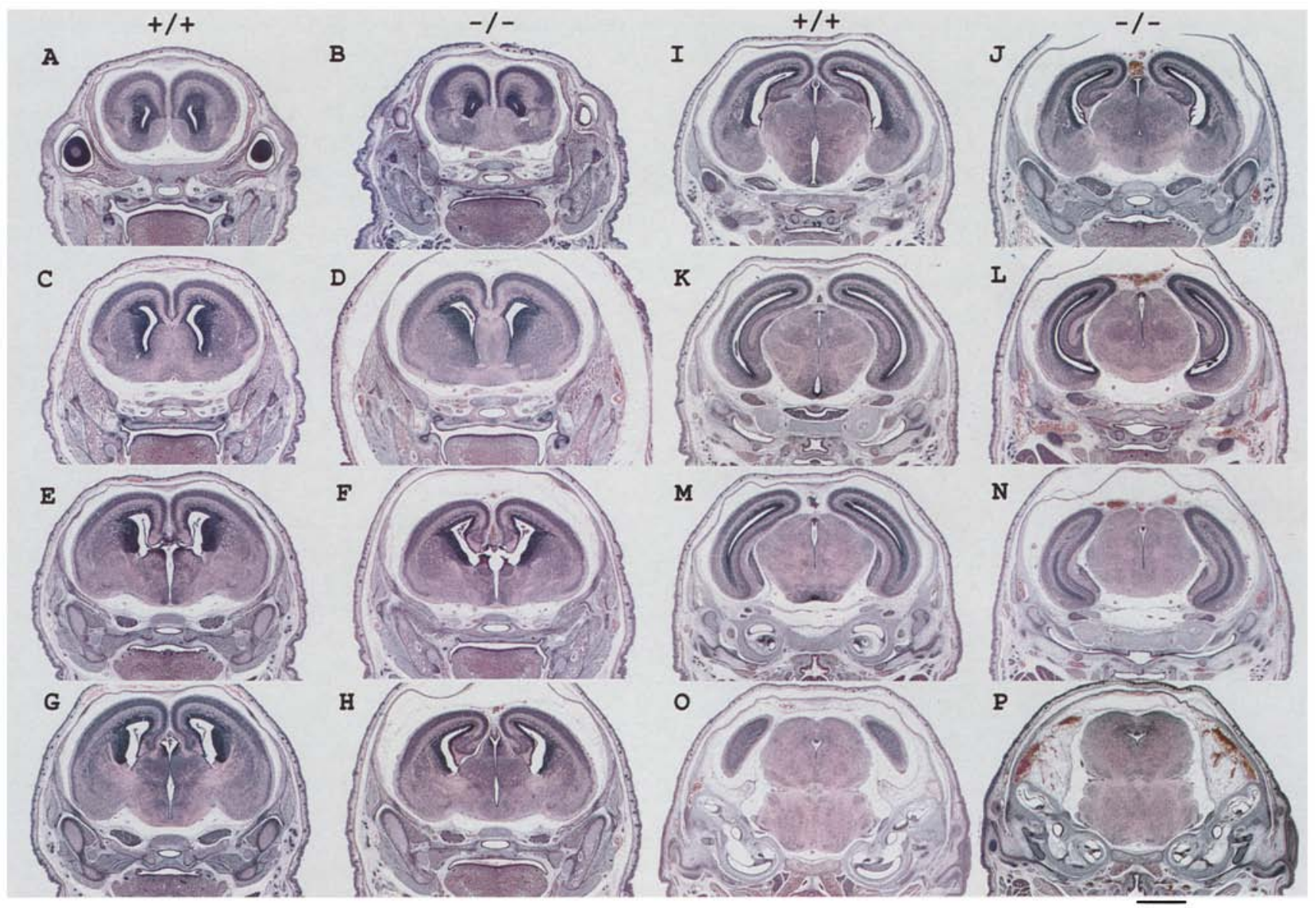

Figure 6. Serial coronal sections of E 18.5 mouse brain. Wild type $(A, C, E, G, I, K, M, O)$ and $T / e b p$ null homozygous mouse brains $(B, D, F, H, J, L, N, P)$ are shown. The levels of coronal sections are indicated as follows: $(A, B)$ The anterior end of the septal area; $(C, D)$ the diagonal band; $(E, F)$ the optic chiasma. (the optic chiasma and suprachiasmatic nuclei are present in the homozygous mouse); $(G, H)$ the paraventricular nucleus (the supraoptic and paraventricular nuclei are seen in the homozygous mouse); $(I, I)$ the tuberal hypothalamus (the ventromedial and dorsomedial nuclei are apparently fused in the homozygous mouse); $(K, L)$ the premammillary nucleus (the entire pituitary is missing in the homozygous mouse); $(M, N)$ the mammillary body (no mammillary body is found in the homozygous mouse); $(O, P)$ the midbrain. Scale bar, $1 \mathrm{~mm}$.

enohypophysis, consisting of the anterior pituitary and the intermediate pituitary, is derived from an outpouching of the oral epithelium from the roof of the primitive buccal cavity that begins to migrate upward toward the developing diencephalon. This epithelial extension is known as Rathke's pouch. The neurohypophysis is derived from the infundibulum, a down-growth from the floor of the primordial diencephalon. At E9.5-10 in mice the anterior wall of Rathke's pouch is in direct apposition with the floor of the diencephalon (Schwind 1927; Rugh 1968; Kaufman 1992). There has been a debate focused on the possibility that the floor of the diencephalon may be "induced" to form the neurohypophysis by the presence of the Rathke's pouch, or vice versa (Nemeskéry et al. 1976; Daikoku et al. 1982, 1983; Watanabe 1982a,b). In normal E11-13 mouse embryos (this study) and rat embryos (Lazzaro et al. 1991), T/ebp gene expression was located only in the floor of the diencephalon and the infundibulum but not in the epithelium of Rathke's pouch. Of most interest is the finding that the absence of $T / e b p$ gene expression totally abolished for- mation of the anterior and intermediate pituitary gland, which do not express the $T / e b p$ gene. This clearly suggests that the presence of the infundibulum and/or T/ebp gene expression in the infundibulum may induce Rathke's pouch to fully develop into the anterior and intermediate pituitary.

Our results showed further that despite the lack of normal hypothalamus and pituitary, the T/ebp null homozygous mice developed full term in their mother's womb with only a slight decrease in body weight at birth. These results suggest that all of the hormones and molecules that are essential for global growth and survival of the fetus may be supplied by the mother through the placenta.

The differentiated thyroid and lung are characterized by the expression of differentiation marker genes such as thyroid peroxidase, thyroglobulin, and TSH receptor in thyroid and surfactant proteins A and B in lung, respectively. Expression of all these genes is controlled by T/EBP, and the T/ebp gene is expressed in the thyroid and lung in the adult and during development. The thy- 


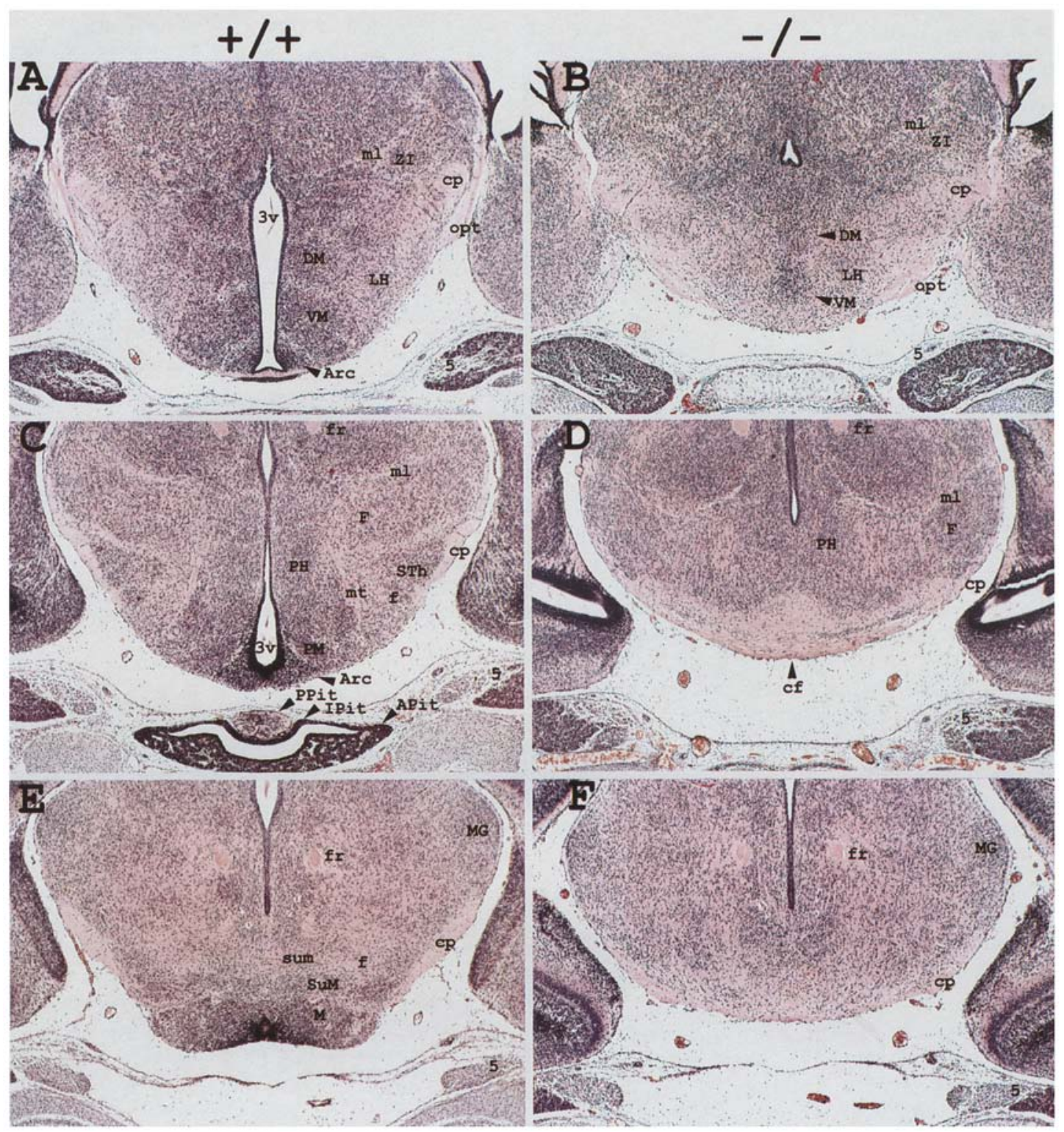

Figure 7. Defects in the ventral area of the posterior hypothalamus and pituitary. Coronal sections of wild type $(A, C, E)$ and $T / e b p$ null homozygous $(B, D, F)$ mouse brains are shown. Because of extensive malformations in the posterior hypothalamus of the mutant mouse brain, precise comparisons at the same level between wild-type and T/ebp null homozygous mouse brains cannot be made. $(A, B)$ The ventromedial (VM) and dorsomedial (DM) nuclei are underdeveloped and appear to be fused in the midline in the T/ebp null homozygous mice. $(C, D)$ The arcuate (Arc) and premammillary (PM) nuclei are almost absent in the homozygous mouse brain. On the floor of the diencephalon, unidentified crossing fibers (cf), distinct from the optic tract (opt), are seen, apparently from the cerebral peduncle (cp). Completely missing are the anterior (APit) and intermediate pituitary (IPit), which are derived from the oral epithelium, and the posterior pituitary (PPit) originated from the ventral hypothalamus. $(E, F)$ The mammillary body $(M)$ and supramammillary nucleus (SuM) are completely absent in the homozygous mouse brain. Throughout the preoptic and hypothalamic areas, the deformity in the lateral and dorsal areas is seen at much lesser extent as compared to the medial and ventral areas. Scale bar, $1 \mathrm{~mm}$. Abbreviations: (3v) Third ventricle; (5) Trigeminal ganglion and nerve; (APit) Anterior pituitary; (Arc) Arcuate nucleus; (cf) unidentified crossing fibers; (cp) cerebral peduncle; (DM) dorsomedial nucleus; (F) fields of Forel; (f) fornix; (fr) fasciculus retroflexus; (IPit) intermediate pituitary; $(\mathrm{MG})$ medial geniculate nucleus; $(\mathrm{LH})$ lateral hypothalamic area; $(\mathrm{M})$ mammillary body; (ml) medial leminiscus; (mt) mammillothalamic tract; (opt) optic tract; (PH) posterior hypothalamic area; (PM) premammillary nucleus; (PPit) posterior pituitary; (STh) subthalamic nucleus; (SuM) supramammillary nucleus; (sum) supramammillary decussation; (VM) ventromedial nucleus; (ZI) zona incerta.

roid differentiation maker proteins are observed in the immature thyroid cells 5 days after the appearance of T/EBP transcript and protein during rat embryogenesis (Lazzaro et al. 1991). Thus, T/EBP seems to have at least two distinct functions: (1) determination of cell commitment to become thyroid or lung, and (2) regulation of gene expression in the differentiated thyroid or lung cells. Our present results suggest that this situation may 


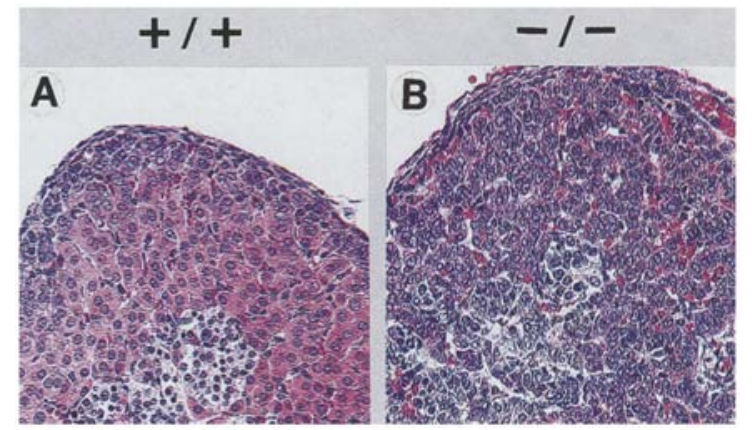

Figure 8. Histological analysis of the adrenal cortex. Neonatal wild-type $(A)$ and homozygous $(B)$ adrenal glands were fixed in $4 \%$ paraformaldehyde and subjected to $H \& E$ staining. The hypoplastic cells with scant cytoplasm are seen in the zona fasciculata of the adrenal cortex in the homozygous mouse.

also be the case for the ventral forebrain. It is possible that T/EBP may regulate expression of additional genes that are directly involved in development and/or differentiation of the thyroid, lung, and central nervous system. The expression of these genes may be important for initial commitment of cells and/or for differentiation and survival of the cells during embryonic development of the thyroid, lung, and hypothalamic neurons.

In summary, our results document the essential role of the gene encoding T/EBP in the embryonic differentiation of the thyroid, lung, ventral forebrain, and pituitary. The T/EBP-deficient animals will provide an excellent model system to study the molecular mechanisms involved in the complex differentiation of these organs. Whether there are any additional genes required for early events in the development of the organs and how these genes interact to direct differentiation remains to be understood.

\section{Materials and methods}

\section{Construction of the targeting vector}

The pMC1-neo cassette was obtained from pMC1-neo poly(A) (Stratagene Cloning Systems) by digestion with BamHI, followed by blunt-ending with DNA polymerase I Klenow fragment, ligation to $X$ hoI linkers, and finally, release of the fragment by $X$ hol digestion. The $1.1-\mathrm{kb}$ neo cassette was then inserted into the XhoI site present in the coding sequence of the $T / e b p$ gene to generate $\mathrm{pTE}(\mathrm{neo})$. The insertion of the neo cassette disrupts the three-dimensional structure of the homeo domain because the XhoI site is located in the middle of helix I in the homeo domain sequence (Guazzi et al. 1990). This would be expected to disrupt the DNA-binding ability of the protein. A 1.9-kb XhoI-SalI thymidine kinase cassette, under the control of the herpes simplex virus promoter (obtained from Dr. $\mathrm{H}$. Westphal, National Institute of Child Health and Human Development, Bethesda, MD|, was subcloned into the Sall site of $\mathrm{pTE}($ neo) to generate the targeting vector pTE(neo)tk (Fig. 1A).

\section{Electroporation and selection of ES cells}

The Jl ES cell line was cultured on embryonic fibroblast feeder cells as described (Li et al. 1992). Electroporation of $1 \times 10^{7}$ ES cells was performed with $25 \mu \mathrm{g} / \mathrm{ml}$ of linearized targeting vec- tor (Bio-Rad gene pulser set at $250 \mathrm{~V}, 250 \mu \mathrm{F}$ ), and cells were selected in the presence of $0.3 \mathrm{mg} / \mathrm{ml}$ of G418 and $5 \mu \mathrm{M}$ gancyclovir (provided by Syntex, Palo Alto, CA). Surviving colonies were isolated and expanded, and genomic DNA was purified for Southern blot analyses.

\section{Southern blot analyses}

Genomic DNA samples from ES cell colonies and mouse tails were prepared as described (Laird et al. 1991). They were digested with StuI, the DNA was separated in agarose gels, and analyzed for the disrupted T/ebp allele by Southern blotting. Probes included a 400-bp BamHI-SphI fragment of the T/ebp gene (see Fig. 1A for the position of the probe) and the $1.1-\mathrm{kb}$ BamHI-Xhol neo fragment of pMCl-neo poly(A).

\section{Generation of chimeras}

Embryo manipulations and injection of ES cell clones into B6 mouse blastocysts were carried out as described (Bradley 1987). Chimeric animals with a high contribution of $129 / \mathrm{Sv}$ genetic background, as judged from coat color, were bred with B6 mice. Offspring heterozygous for the disrupted $T / e b p$ gene, reflecting germ-line transmission of the targeted T/ebp allele, were mated to each other to produce potential $T / e b p$ null mice.

\section{Histological analyses}

Immediately after delivery, dead neonates were necropsied. Healthy littermates were sacrificed by asphyxiation with $\mathrm{CO}_{2}$ and necropsied. In certain experiments, embryos were obtained by dissection of pregnant mice at specific stages of pregnancy [noon of the day at which the copulatory plug was detected was designated as embryonic day 0.5 (E0.5)]. Appropriate staging of animals was determined based on those described by Kaufman (1992). Whole E18.5 embryos or neonates were fixed in either $10 \%$ buffered formalin or Bouin's solution for 2-3 days and then transferred to $70 \%$ ethanol. A solution of $4 \%$ paraformaldehyde in PBS ( $\mathrm{pH} 7.2$ ) was used to fix some embryos (E1 1-13) for 2-4 hr for in situ hybridization or histological analyses. After identification of genotypes by tail DNA analyses, embryos were embedded in paraffin, sectioned serially at $5 \mu \mathrm{m}$, and stained with hematoxylin and eosin or by using the Periodic acid-Schiff method.

\section{In situ hybridization}

The probe for in situ hybridization was a $1.4-\mathrm{kb}$ fragment that contains the sequence of the entire first exon, $87 \mathrm{bp}$ from the $5^{\prime}$ end of the second exon, and an intron of the mouse $T / e b p$ gene (Oguchi et al. 1995). This intronic sequence hybridized intensely on Northern blots to a higher molecular weight band that corresponds to one of the bands that hybridize to the homeo domain sequence (Mizuno et al. 1991). The 1.4-kb fragment was prepared using PCR, having an EcoRI site at the 5' end and a HindIII site at the $3^{\prime}$ end. The EcoRI-HindIII fragment was then inserted into pGEM-3Z which had been digested previously with EcoRI and HindIII. The construct was linearized at EcoRI or HindIII site to obtain the antisense or sense strands under the direction of the SP6 or T7 promoter, respectively, in an in vitro transcription reaction.

In situ hybridization was carried out as described (Fox and Cottler-Fox 1993|. Briefly, paraffin sections were dewaxed and hydrated, blocked in acetic anhydride and succinic anhydride, and hybridized with $\left.{ }^{35} \mathrm{~S}\right] \mathrm{CTP}$-labeled sense and antisense riboprobes prepared using the constructs as described above. Following RNase digestion and exhaustive stringent washings, the slides were coated with Kodak NTB2 emulsion followed by ex- 
posure for 4 days. The slides were then developed in diluted D-19.

\section{Acknowledgments}

We thank Dr. Kathleen A. Mahon for her critical review of the manuscript. We also thank Dr. Ute Hochgeschwender for supplying the Jl ES cells originally developed in Dr. R. Jaenisch's laboratory (Li et al. 1992). We are very grateful to Dr. Jennifer A. Burris for her help at earlier stages of the work, Debbie Devor for excellent dissection, Joann May, Roberta Smith, James Watson, and Barbara Kasprzak for histology, and Shelley Hoover for in situ hybridization.

The publication costs of this article were defrayed in part by payment of page charges. This article must therefore be hereby marked "advertisement" in accordance with 18 USC section 1734 solely to indicate this fact.

\section{References}

Abramowicz, M.J., G. Vassart, and D. Christophe. 1992. Functional study of the human thyroid peroxidase gene promoter. Eur. I. Biochem. 203: 467-473.

Altman, J. and S.A. Bayer. 1995. Atlas of prenatal rat brain development. CRC Press, Boca Raton, FL.

Bayer, S.A. and J. Altman. 1995a. Neurogenesis and neuronal migration. In The rat nervous system (ed. G. Paxinos), pp. 1041-1078. Academic Press, San Diego, CA.

- 1995b. Principles of neurogenesis, neuronal migration, and neural circuit formation. In The rat nervous system (ed. G. Paxinos), pp. 1079-1098. Academic Press, San Diego, CA.

Bohinski, R.J., R. Di Lauro, and J.A. Whitsett. 1994. The lungspecific surfactant protein $B$ gene promoter is a target for thyroid transcription factor 1 and hepatocyte nuclear factor 3 , indicating common factors for organ-specific gene expression along the foregut axis. Mol. Cell. Biol. 14: 5671-5681.

Bradley, A. 1987. Production and analysis of chimaeric mice. In Teratocarcinomas and embryonic stem sells: A practical approach (ed. E.J. Robertson), pp. 113-151. IRL Press, Oxford, UK.

Bruno, M.D., R.J. Bohinski, K.M. Huelsman, J.A. Whitsett, and T.R. Korfhagen. 1995. Lung cell-specific expression of the murine surfactant protein A (SP-A) gene is mediated by interactions between the $S P$ - $A$ promoter and thyroid transcription factor-1. J. Biol. Chem. 270: 6531-6536.

Capen, C.C., R.A. DeLellis, and J.T. Yarrington. 1991. Endocrine system. In Handbook of toxicologic pathology (ed. W.M. Haschek and C.G. Rousseaux|, pp. 675-760. Academic Press, San Diego, CA.

Civitareale, D., R. Lonigro, A.J. Sinclair, and R. Di Lauro. 1989. A thyroid-specific nuclear protein essential for tissue-specific expression of the thyroglobulin promoter. EMBO $/$. 8: $2537-2541$.

Civitareale, D., M.P. Castelli, P. Falasca, and A. Saiardi. 1993. Thyroid transcription factor 1 activates the promoter of the thyrotropin receptor gene. Mol. Endocrinol. 7: 1589-1595.

Daikoku, S., M. Chikamori, T. Adachi, and Y. Maki. 1982. Effect of the basal diencephalon on the development of Rathke's pouch in rats: a study in combined organ cultures. Dev. Biol. 90: 198-202.

Daikoku, S., M. Chikamori, T. Adachi, Y. Okamura, T. Nishiyama, and T. Yoshihiro. 1983. Ontogenesis of hypothalamic immunoreactive ACTH cells in vivo and in vitro: Role of Rathke's pouch. Dev. Biol. 97: 81-88.

DeGroot, L.J. and H. Niepomniszcze. 1977. Biosynthesis of thyroid hormone: Bases and clinical aspects. Metabolism 26: $665-718$.
Fox, C.H. and M. Cottler-Fox. 1993. In situ hybridization for detection of HIV RNA. In Current protocols in immunology (ed. J.E. Coligan, A.M. Kruisbeek, D.H. Margulies, E.M. Shevach, and W. Strober), pp. 12.8.1-12.8.21. Green Publishing Associates/John Wiley \& Sons, New York, NY.

Francis-Lang, H., M. Price, M. Polycarpou-Schwarz, and R. Di Lauro. 1992. Cell-type-specific expression of the rat thyroperoxidase promoter indicates common mechanisms for thyroid-specific gene expression. Mol. Cell. Biol. 12: 576-588.

Guazzi, S., M. Price, M. De Felice, G. Damante, M.-G. Mattei, and R. Di Lauro. 1990. Thyroid nuclear factor 1 (TTF-1) contains a homeodomain and displays a novel DNA binding specificity. EMBO \%. 9: 3631-3639.

Kaufman, M.H. 1992. The atlas of mouse development. Academic Press, London, UK.

Kikkawa, F., F.J. Gonzalez, and S. Kimura. 1990. Characterization of a thyroid-specific enhancer located 5.5 kilobase pairs upstream of the human thyroid peroxidase gene. Mol. Cell. Biol. 10: 6216-6224.

Kim, Y. and M. Nirenberg. 1989. Drosophila NK-homeobox genes. Proc. Natl. Acad. Sci. 86: 7716-7720.

Laird, P.W., A. Zijderveld, K. Linders, M.A. Rudnicki, R. Jaenisch, and A. Berns. 1991. Simplified mammalian DNA isolation procedure. Nucleic Acids Res. 19: 4293.

Lazzaro, D., M. Price, M. De Felice, and R. Di Lauro. 1991. The transcription factor TTF-1 is expressed at the onset of thyroid and lung morphogenesis and in restricted regions of the foetal brain. Development 113: 1093-1104.

Li, E., T.H. Bestor, and R. Jaenisch. 1992. Targeted mutation of the DNA methyltransferase gene results in embryonic lethality. Cell 69: 915-926.

Lints, T.J., L.M. Parsons, L. Hartley, I. Lyons, and R.P. Harvey. 1993. $N k x-2.5$ : A novel murine homeobox gene expressed in early heart progenitor cells and their myogenic descendants. Development 119: 419-431.

Mizuno, K., F.J. Gonzalez, and S. Kimura. 1991. Thyroid-specific enhancer-binding protein (T/EBP): cDNA cloning, functional characterization, and structural identity with thyroid transcription factor TTF-1. Mol. Cell. Biol. 11:4927-4933.

Nemeskéry, A., A. Németh, G. Sétáló, S. Vigh, and B. Halász. 1976. Cell differentiation of the fetal rat anterior pituitary in vitro. Cell Tiss. Res. 170: 263-273.

Oguchi, H., Y.-T. Pan, and S. Kimura. 1995. The complete nucleotide sequence of the mouse thyroid-specific enhancerbinding protein (T/EBP) gene: Extensive identity of the deduced amino acid sequence with the human protein. Biochim. Biophys. Acta 1261: 304-306.

Price, M., D. Lazzaro, T. Pohl, M.-G. Mattei, U. Rüther, J.-C. Olivo, D. Duboule, and R. Di Lauro. 1992. Regional expression of the homeobox gene $N k x-2.2$ in the developing mammalian forebrain. Neuron 8: 241-255.

Rugh, R. 1968. The mouse. Its reproduction and development. Burgess Publishing Company, Minneapolis, MN.

Schwind, J.L. 1927. The development of the hypophysis cerebri of the albino rat. Am. J. Anat. 41: 295-315.

Shimura, H., F. Okajima, S. Ikuyama, Y. Shimura, S. Kimura, M. Saji, and L.D. Kohn. 1994. Thyroid-specific expression and cyclic adenosine $3^{\prime}, 5^{\prime}$-monophosphate autoregulation of the thyrotropin receptor gene involves thyroid transcription factor-1. Mol. Endocrinol. 8: 1049-1069.

Watanabe, Y.G. 1982a. Effects of brain and mesenchyme upon the cytogenesis of rat adenohypophysis in vitro. Cell Tiss. Res. 227: 257-266.

- $1982 \mathrm{~b}$. An organ culture study on the site of determination of ACTH and LH cells in the rat adenohypophysis. Cell Tiss. Res. 227: 267-275. 


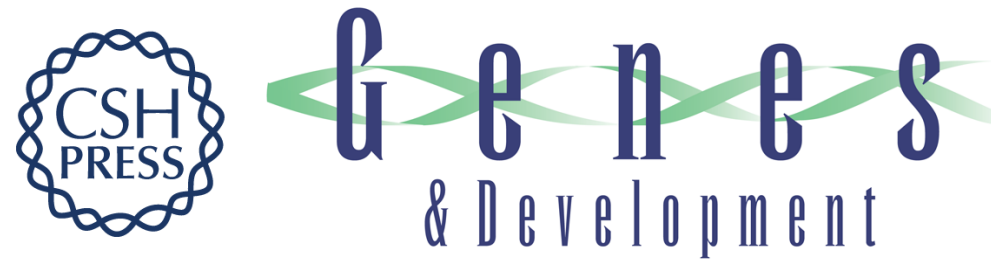

\section{The T/ebp null mouse: thyroid-specific enhancer-binding protein is essential for the organogenesis of the thyroid, lung, ventral forebrain, and pituitary.}

S Kimura, Y Hara, T Pineau, et al.

Genes Dev. 1996, 10:

Access the most recent version at doi:10.1101/gad.10.1.60 $\begin{array}{ll}\text { References } & \text { This article cites } 24 \text { articles, } 8 \text { of which can be accessed free at: } \\ \text { http://genesdev.cshlp.org/content/10/1/60.full.html\#ref-list-1 }\end{array}$

License

Email Alerting Service

Receive free email alerts when new articles cite this article - sign up in the box at the top right corner of the article or click here.

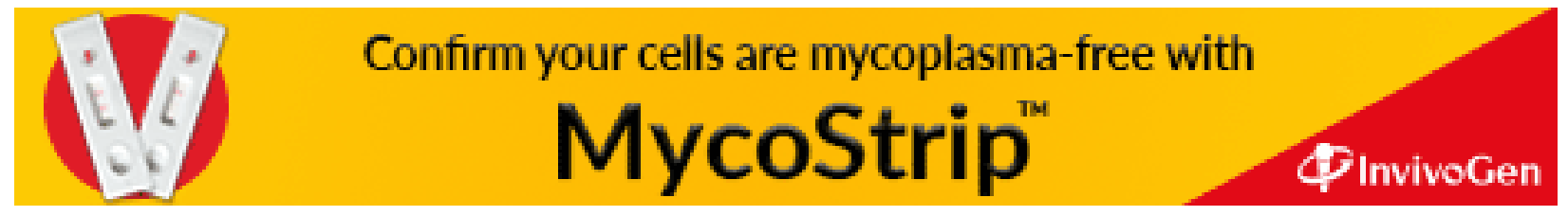

